\title{
The influence of retransplantation on survival for pediatric lung transplant recipients
}

\author{
Ryuichi Waseda, MD, PhD, ${ }^{\text {a,b }}$ Alberto Benazzo, MD, ${ }^{a}$ Konrad Hoetzenecker, MD, PhD, ${ }^{a}$ \\ Peter Jaksch, MD, ${ }^{\mathrm{a}}$ Gabriela Muraközy, MD, ${ }^{\mathrm{a}}$ Saskia Gruber, MD, ${ }^{\mathrm{c}}$ Georg Roth, MD, ${ }^{\mathrm{d}}$ \\ Zsolt Szepfalusi, $\mathrm{MD},{ }^{\mathrm{c}}$ Edith Nachbaur, $\mathrm{MD},{ }^{\mathrm{c}}$ and Walter Klepetko, $\mathrm{MD}^{\mathrm{a}}$
}

\section{ABSTRACT}

Objectives: We reviewed our 25-year experience in pediatric lung transplantation with the aim to identify trends and influencing factors over time.

Methods: We reviewed our prospectively maintained database and analyzed all patients younger than age 18 years who underwent primary lung transplantation at Medical University of Vienna between 1990 and 2015.

Results: Eighty-six consecutive patients were enrolled with a mean age of $12.9 \pm 4.1$ years at primary transplantation. The most frequent indication for primary transplantation was cystic fibrosis (64.0). Bilateral double-lung transplantation was performed in 84 patients $(97.7 \%)$, including lobar transplantation in 35 patients $(40.7 \%)$. sixty-eight patients $(79.1 \%)$ underwent transplant on venoarterial extracorporeal membrane oxygenation and 7 patients $(8.1 \%)$ utilized cardiopulmonary bypass. The 30-day and in-hospital mortality was $8.1 \%$ and $17.4 \%$, respectively, and 1-, 5-, and 10-year overall survival (OS) was 79.0\%, 67.5\%, and $57.1 \%$, respectively. A significant improvement of OS was observed during the second treatment period after 2003 with a 1-, 5-, and 10-year OS of $86.0 \%$, $73.9 \%$, and $73.9 \%$, respectively $(P<.01)$. Seventeen retransplantations were performed in 14 patients. Twelve patients $(85.7 \%)$ underwent 15 late elective retransplantations for chronic lung allograft dysfunction resulting in a 1- and 5-year OS of $91.7 \%$ and $80.2 \%$, respectively. In contrast, 2 patients $(14.3 \%)$ who underwent acute retransplantation for primary graft failure died during the postoperative period.

Conclusions: Our outcomes for pediatric lung transplantation have improved over the past 25 years and have become comparable to those for adult transplantation. Elective re-transplantations for pediatric patients were performed successfully, and strongly influenced improved long-term OS. (J Thorac Cardiovasc Surg 2018;156:2025-34)

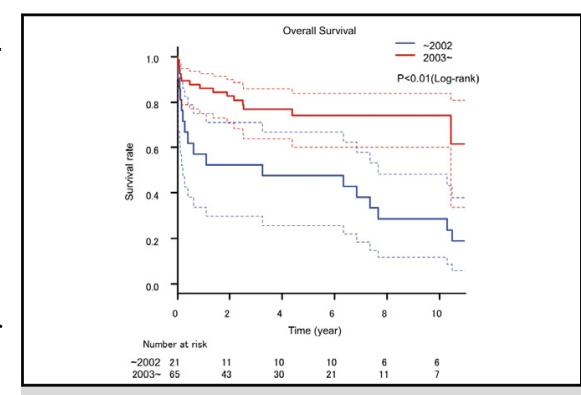

Overall survival in the second period was significantly superior to that in the first period.

\section{Central Message}

Long-term survival of pediatric lung transplantation has significantly improved over the past 25 years. That may be due to improved perioperative outcome and liberal retransplantation for CLAD.

\section{Perspective}

Pediatric lung transplantation remains less standardized than adult transplantation. Only limited data on outcome and risk factors of this special patient population are available. This large, single-center experience covering 25 years of pediatric lung transplantation showed that outcome significantly improved over time and overall survival is comparable to survival rates from adult populations.

See Editorial Commentaries pages 2035 and 2037.

See Editorial page 2023.

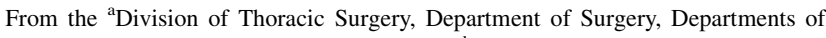
${ }^{\mathrm{c}}$ Pediatrics and Adolescent Medicine and ${ }^{\mathrm{d}}$ Anesthesiology and Intensive Care, Medical University of Vienna, Vienna, Austria; and ${ }^{\mathrm{b}}$ Department of General Thoracic, Breast, and Pediatric Surgery, Fukuoka University, Fukuoka, Japan. Received for publication Dec 4, 2017; revisions received April 30, 2018; accepted for publication May 2, 2018; available ahead of print July 7, 2018.

Address for reprints: Walter Klepetko, MD, Division of Thoracic Surgery, Department of Surgery, Medical University of Vienna, Waehringer Guertel 18-20, Vienna, Austria (E-mail: walter.klepetko@meduniwien.ac.at). $0022-5223 / \$ 36.00$

Copyright (c) 2018 by The American Association for Thoracic Surgery https://doi.org/10.1016/j.jtcvs.2018.05.080
}

The first successful pediatric lung transplantation was performed in Toronto in 1987, and until now remains a scarcely performed procedure. ${ }^{1}$ Only about 2000 cases have been

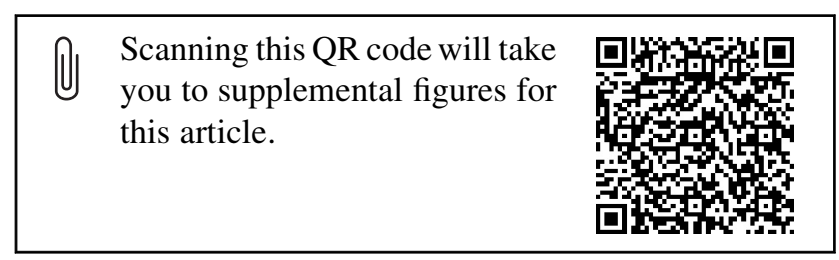




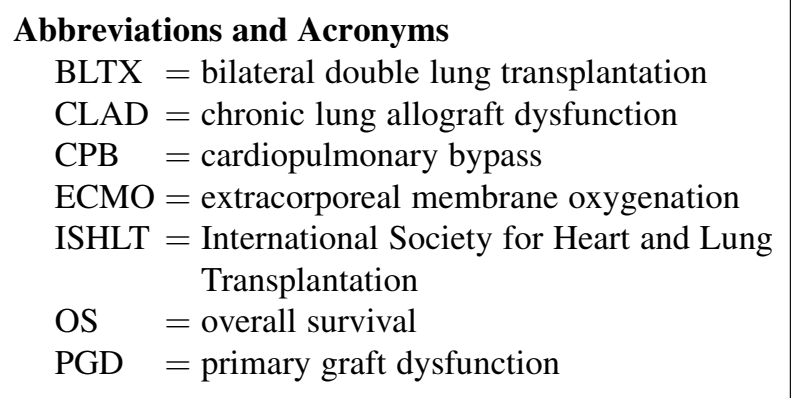

reported to the registry of the International Society for Heart and Lung Transplantation (ISHLT) so far, and the annual number of about 120 cases remains low. ${ }^{2}$ Even more important, this small number of procedures is performed by approximately 45 centers, which implies that the number to center ratio is very low and hardly any center with a case-

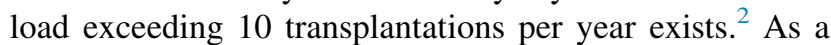
consequence, pediatric lung transplantation remains much less standardized than adult transplantation and the existing data on outcome and risk factors are limited. ${ }^{3,4}$ Because our center has a 25-year experience with a stable annual number of 5 to 9 procedures during recent years, we reviewed our results and experiences with this specific procedure.

\section{METHODS}

The study was approved by the institutional review board of the Medical University of Vienna. All relevant data were retrieved and analyzed from our institutional database, which was maintained prospectively by our Department of Pediatrics and Adolescent Medicine, focusing on our treatment strategy and effects of retransplantation. The study population consisted of all consecutive pediatric patients (age $<18$ years at the primary transplantation) who underwent isolated lung transplantation at the Division of Thoracic Surgery, Department of Surgery, Medical University of Vienna, between April 1990 and December 2015.

\section{Data Collection and Statistical Analysis}

All parameters related to primary lung transplantation as well as retransplantation were collected and analyzed in this study. Pretransplant parameters included age, sex, body mass index, underlying disease, lung function, wait time, in-hospital admission before transplantation, preoperative mechanical ventilation, and preoperative extracorporeal membrane oxygenation (ECMO) support. Surgical and peritransplant parameters included the type of transplant procedure, intraoperative extracorporeal support (ECMO or cardiopulmonary bypass [CPB]), donor factors (eg, age, sex, and ischemia time), and immunosuppression such as type of calcineurin inhibitor and use of induction therapy. Posttransplant parameters were duration of intensive care unit stay, posttransplant intubation time, postoperative ECMO support, total in-hospital time, posttransplant complications (eg, hemorrhage, infection, primary graft dysfunction [PGD], and neurologic complications), need for tracheostomy, revision surgery and renal replacement therapy, occurrence of acute rejection, and chronic lung allograft dysfunction (CLAD), and causes of late graft failure and death. Follow-up for pediatric patients was performed by a dedicated team of pulmonologists from the Department of Pediatrics and Adolescent Medicine or after transition by adult transplant pulmonologists from the Department of Thoracic Surgery. All patients were followed on a regular basis; therefore, complete information on long-term vital status and organ function was available for every patient.

To analyze the change of our experience, the treatment period was divided into 2 equal time periods of 13 years (1990-2002 and 2003-2015). Differences between the 2 time periods were calculated by 1-way analysis of variance or $\chi^{2}$ test. Overall survival (OS) and organ survival were calculated using a Kaplan-Meier method with log-rank test. Additionally, cumulative incidence of graft death and CLAD were also calculated using a competing risk analysis with Gray's test. Collected parameters were tested with an univariable Cox-regression model for each of the end points to identify risk factors for OS. A multiple-extended Cox-regression model was calculated mainly for each end point being significant and marginally significant in the univariable analysis $(P<.1)$. In multivariable analysis, postoperative factors were excluded to identify true independent risk factors. Regarding risk factor analysis of organ survival, both univariable and multivariable analyses were performed using the Fine-Gray method. All analyses were performed using SPSS version 24.0 (IBM-SPSS Inc, Armonk, NY).

\section{Treatment Strategy}

Donor selection, size matching, and organ retrieval. The principles of donor selection were in general comparable to those used in adult transplantation. Donors were evaluated according to age, available medical records, blood gas analysis, plain chest radiography, and findings during bronchoscopy and harvesting. Blood group compatibility was a prerequisite, and donor/recipient matching was based primarily on size (ie, height, sex, and total lung capacity). Additional factors such as age, urgency of the recipient, underlying disease, and estimated ischemia time were taken into account. Organ retrieval did not differ from our standard method for adult lung transplantation. An amount of $1.5 \mathrm{mg}$ prostacyclin was given intravenously before aorta clamp, then the organ was perfused with $6 \mathrm{~L}$ Perfadex (XVIVO Perfusion AB, Göteborg, Sweden) in an antegrade manner under topical cooling. Retrograde perfusion with $3 \mathrm{~L}$ Perfadex was performed at the backtable. Before 2002, Euro-Collins solution was used to perfuse organs. Standard surgical technique. The standard technique for lung transplantation in pediatric patients was bilateral sequential lung transplantation. In few patients, unilateral transplantation was performed when required by special indications. The technique and management did not differ from that applied in the adult population with the exception of a few specific aspects and details.

Size-reduced procedures, including lobar transplantation. Due to the scarcity of pediatric donor lungs, downsizing of oversized donor lungs was performed for a high percentage of patients. In case of a minor size mismatch of up to $20 \%$ of total lung capacity, nonanatomic resection of the middle lobe and/or the lingula was performed. In case of a more pronounced size discrepancy, anatomic lobar transplantation was performed. Split-lung transplantations (ie, separating a left donor lung, followed by bilateral lobar transplantation) and living-donor lobar transplantations were also performed in this series.

Use of extracorporeal support. Except for the early period of time when CPB was used whenever necessary, intraoperative extracorporeal support with central venoarterial ECMO was our standard treatment. In some patients, the intraoperative ECMO was transferred into the groin and prolonged into the postoperative period when indicated by patient instability or limited initial graft function. Criteria for prolongation were marginal quality of the donor organ, increasing need for more aggressive ventilation at the end of the intraoperative ECMO support, or a high-risk recipient. Venovenous $(n=3)$ and venoarterial $(n=6)$ ECMO was also used as a bridging device to transplantation in 9 patients.

Immunosuppression. Immunosuppression varied over the 25-year period. Whereas in the beginning routine immunosuppression consisted of a cyclosporine/azathioprine-based triple-drug therapy, later on a tacrolimus/mycophenolat triple-drug therapy became the standard treatment. Induction therapy with monoclonal antibodies was increasingly used over the period of time and was part of the analysis. 


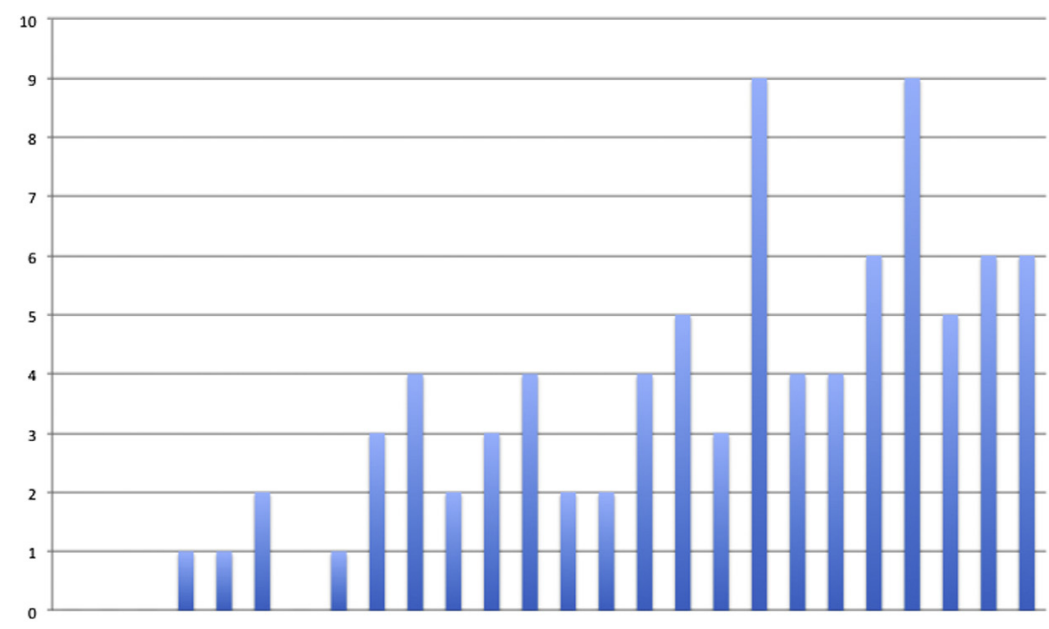

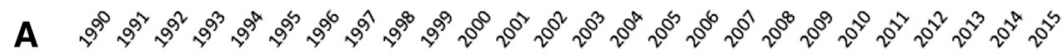

B

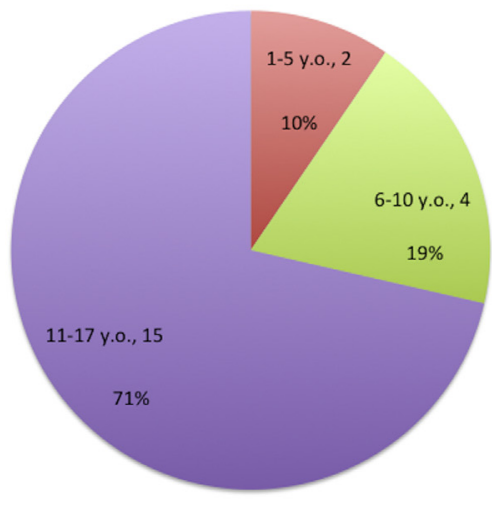

$<2002$

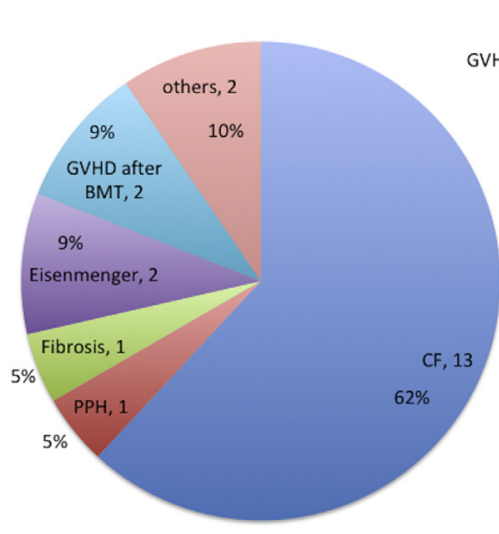

C

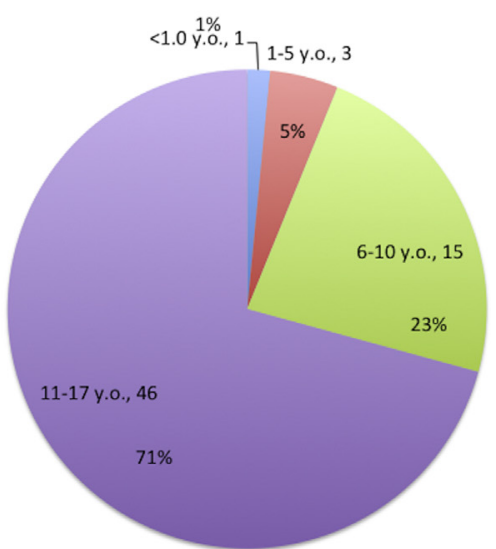

$2003<$

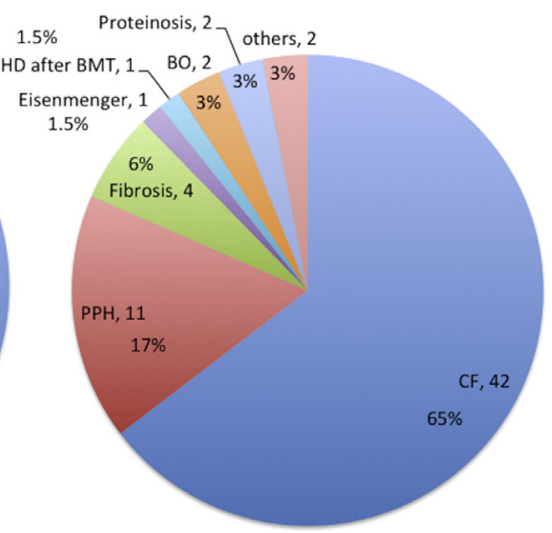

$2003<$

FIGURE 1. Pediatric lung transplantations performed at the Medical University of Vienna. A, Timeline. B, Age distribution (before 2002, left, and after 2003, right). C, Indications for transplant (before 2002, left, and after 2003, right). y.o., Years old; GVHD, graft versus host disease; BMT, bone marrow transplantation; $P P H$, primary pulmonary hypertension; $C F$, cystic fibrosis; $B O$, bronchiolitis obliterans. 


\section{RESULTS}

Eighty-six consecutive patients who underwent primary lung transplantation at our center were included in this analysis. The annual number of pediatric procedures is demonstrated in Figure 1, A. A constant increase was observed over time, resulting in a frequency of 5 to 9 procedures per year during the past 5 years. Mean age of patients was 12.9 years (range, 6 months- 17.9 years). The number of children aged $\leq 5$ years was $6(7.0 \%)$, those aged between 6 and 10 years was $19(22.1 \%)$, and those aged $\geq 11$ years was $61(70.9 \%)$. Age brackets at primary lung transplantation were similar between the 2 time periods (Figure 1, B). Details of the underlying diseases are summarized in Figure 1, $C$. The most common indication was cystic fibrosis $(64.0 \%)$ followed by primary pulmonary hypertension $(14.0 \%)$. A noticeable increase of patients with primary pulmonary hypertension was observed during the second period.

Twenty-eight patients $(32.6 \%)$ needed in-hospital management before transplantation; $14(16.3 \%)$ were receiving mechanical ventilation, and $9(10.5 \%)$ required preoperative ECMO support. Data regarding primary lung transplantation are shown in Table 1. Eighty-four patients underwent bilateral double lung transplantation (BLTX), and 2 patients underwent unilateral single lung transplantation. Of 84 patients who underwent BLTX, 39 received standard wholelung transplants, 11 received size-reduced transplants, and 35 received lobar transplants. Among the 35 lobar transplants, 6 patients received BLTX from splitting of a left donor lung into 2 separate lobes. Four patients were transplanted with lobes from living related donors (3 BLTX and 1 single lung transplantation).

The standard intraoperative cardiorespiratory support was venoarterial ECMO, which was used in 68 patients $(79.1 \%)$. In 28 patients $(41.1 \%)$, intraoperative ECMO was prolonged into the early postoperative period. CPB was used in 7 patients $(8.1 \%)$, the majority being transplanted during the early time. Only 11 patients $(12.8 \%)$ underwent transplant without any intraoperative extracorporeal support.

TABLE 1. All parameters related to primary lung transplantation

\begin{tabular}{|c|c|c|c|c|}
\hline & $\begin{array}{r}\text { Overall } \\
(\mathbf{n}=\mathbf{8 6})\end{array}$ & $\begin{array}{l}\text { First era }(1990-2002) \\
\quad(n=21)\end{array}$ & $\begin{array}{l}\text { Second era (2003-2015) } \\
\qquad(\mathbf{n}=\mathbf{6 5})\end{array}$ & $P$ value \\
\hline \multicolumn{5}{|l|}{ Patients characteristics and preoperative factors } \\
\hline Age & $12.9 \pm 4.1$ & $12.8 \pm 4.5$ & $13.0 \pm 3.9$ & .9 \\
\hline Gender (male/female) & $39 / 47$ & 43444 & $29 / 37$ & .46 \\
\hline Underlying disease (cystic fibrosis/no cystic fibrosis) & $55 / 31$ & $13 / 8$ & $42 / 23$ & .82 \\
\hline Body mass index & $14.6 \pm 2.9$ & $15.0 \pm 3.2$ & $14.4 \pm 2.7$ & .47 \\
\hline Waiting time $(\mathrm{d})$ & $103.1 \pm 111.5$ & $78.4 \pm 61.4$ & $113.1 \pm 125.8$ & .35 \\
\hline Preoperative hospitalization & $28(32.6)$ & $11(52.4)$ & $17(26.2)$ & .03 \\
\hline Preoperative ventilation & $14(16.3)$ & $5(23.8)$ & $9(13.8)$ & .28 \\
\hline Preoperative extracorporeal membrane oxygenation & $9(10.5)$ & $3(14.3)$ & $6(9.2)$ & .51 \\
\hline \multicolumn{5}{|l|}{ Surgical and perioperative factors } \\
\hline Type of transplant (unilateral/bilateral) & $2 / 84$ & $0 / 21$ & $2 / 63$ & .42 \\
\hline Transplant procedure (nonlobar/lobar) & $51 / 35$ & $9 / 12$ & $42 / 23$ & .08 \\
\hline Intraoperative extracorporeal support & $75(87.2)$ & $16(76.2)$ & $59(90.8)$ & .08 \\
\hline $\begin{array}{l}\text { Type of intraoperative extracorporeal support (extracorporeal } \\
\text { membrane oxygenation/cardiopulmonary bypass) }\end{array}$ & $68 / 7$ & $10 / 6$ & $58 / 1$ & $<.01$ \\
\hline Donor age & $22.6 \pm 16.9$ & $33.9 \pm 15.8$ & $21.0 \pm 16.3$ & .01 \\
\hline Donor gender (male/female) & $32 / 54$ & $9 / 12$ & $23 / 42$ & .54 \\
\hline Ischemic time & $351.7 \pm 64.6$ & $346.0 \pm 87.1$ & $353.5 \pm 56.3$ & .67 \\
\hline Induction therapy & $59(68.6)$ & $9(42.9)$ & $50(76.9)$ & .01 \\
\hline Immunosuppression (cyclosporine/tacrolimus) & $16 / 70$ & $15 / 6$ & $1 / 64$ & $<.01$ \\
\hline \multicolumn{5}{|l|}{ Postoperative factors } \\
\hline Primary graft dysfunction & $30(34.9)$ & $9(42.9)$ & $21(32.3)$ & .54 \\
\hline Acute rejection & $16(18.6)$ & $5(23.8)$ & $11(16.9)$ & .7 \\
\hline Prolonged extracorporeal membrane oxygenation & $28(32.6)$ & $7(33.3)$ & $21(32.3)$ & .93 \\
\hline Postoperative tracheostomy & $36(41.9)$ & $13(61.9)$ & $23(35.4)$ & .03 \\
\hline Postoperative reoperation & $20(23.3)$ & $5(23.8)$ & $15(23.1)$ & .77 \\
\hline Postoperative renal replacement therapy & $5(5.8)$ & $2(9.5)$ & $3(4.6)$ & .34 \\
\hline 30-d mortality & $7(8.1)$ & $3(14.2)$ & $4(6.2)$ & .24 \\
\hline In-hospital mortality & $15(17.4)$ & $7(33.3)$ & $8(12.3)$ & .03 \\
\hline Chronic lung allograft dysfunction & $16(18.6)$ & $8(38.1)$ & $8(12.3)$ & .01 \\
\hline
\end{tabular}

Values are presented as mean \pm standard deviation, $\mathrm{n} / \mathrm{n}$, or $\mathrm{n}(\%)$. 


\section{Early Outcome}

Outcomes after primary transplantation are summarized in Table 1. Thirty-day mortality and in-hospital mortality of the whole cohort were $8.1 \%$ and $17.4 \%$, respectively. Reasons for early death included neurologic events such as bleeding or infarction, fatal infection followed by multiorgan failure, acute rejection, severe PGD, and bronchial anastomotic dehiscence. Except for a single case of bronchial dehiscence, no other bronchial anastomotic problems needing stent implantation or dilatation occurred in this series. Reoperation was reported for 20 patients. Fifteen patients required a hematoma evacuation for postoperative bleeding. Three patients required a reoperation for wound infection, 1 for empyema, and 1 for pneumothorax.

\section{Late Outcome}

Kaplan-Meier curves depicting OS and organ survival after primary transplantation are shown in Figure 2, A. The 1-, 5 -, and 10-year OS of the whole cohort was 79.0\% $(95 \%$ confidence interval [CI], 70.4\%-87.6\%), 67.5\% (95\% CI, 57.1\%-77.9\%), and 57.1\% (95\% CI, 44.0\%-70.2\%), respectively. The corresponding organ survival of the same cohort was 79.0\% (95\% CI, 70.4\%-87.6), 60.3\% (95\% CI, 49.1\%-71.5\%), and 36.9\% (95\% CI, $22.6 \%-$ $51.2 \%$ ), respectively. Outcomes significantly improved in the treatment period after 2003 with a 1-, 5-, and 10-year OS of $86.0 \%$ (95\% CI, $74.9 \%-92.5 \%), 73.9 \%$ (95\% CI,

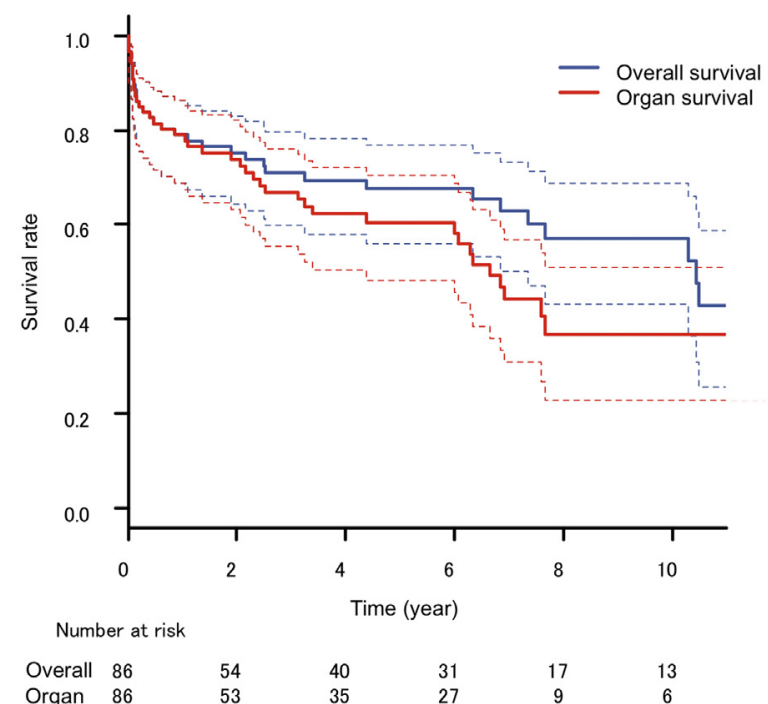

60.0\%-83.6\%), and $73.9 \%$ (95\% CI, 60.0\%-83.6\%), compared with $57.1 \%$ (95\% CI, 33.8\%-74.9\%), $47.6 \%$ (95\% CI, $25.7 \%-66.7 \%$ ), and $28.6 \%$ (95\% CI, $11.7 \%$ $48.2 \%)$ in the early period $(P<.01)$ (Figure $2, B)$. Similarly, organ survival increased to $86.0 \%(95 \%$ CI, $74.9 \%$ $92.5 \%), 69.7 \%(95 \% \mathrm{CI}, 55.2 \%-80.3 \%)$, and $52.1 \%$ (95\% CI, $32.6 \%-68.4 \%$ ) at 1,5 , and 10 years compared with $57.1 \%(95 \%$ CI, 33.8\%-74.9\%), 33.3\% (95\% CI, $14.9 \%-53.1 \%$ ), and $9.5 \%$ (95\% CI, 1.6\%-26.1\%) during the early period (Figure E1) $(P<.01)$. However, a competing risk analysis with Gray's test for organ survival detected only marginal statistical significance (Figure E2) $(P=.09)$. The difference between OS $(73.9 \%)$ and organ survival $(52.1 \%)$ at 10 years was the result of a high number and excellent outcomes of elective retransplantations during the second time period.

The difference between the 2 periods for all the parameters related to lung transplantation is shown in Table 1. Among patient characteristics and pretransplant factors, hospitalization before transplant was less frequent during the second period than during the first period. With regard to surgical and perioperative factors, younger donor age, increased use of induction therapy, and exclusive use of tacrolimus were identified during the second period compared with the first period. In terms of posttransplant factors and outcome, indication for tracheostomy, in-hospital mortality, and occurrence of CLAD were significantly lower during the second period compared with the first period.

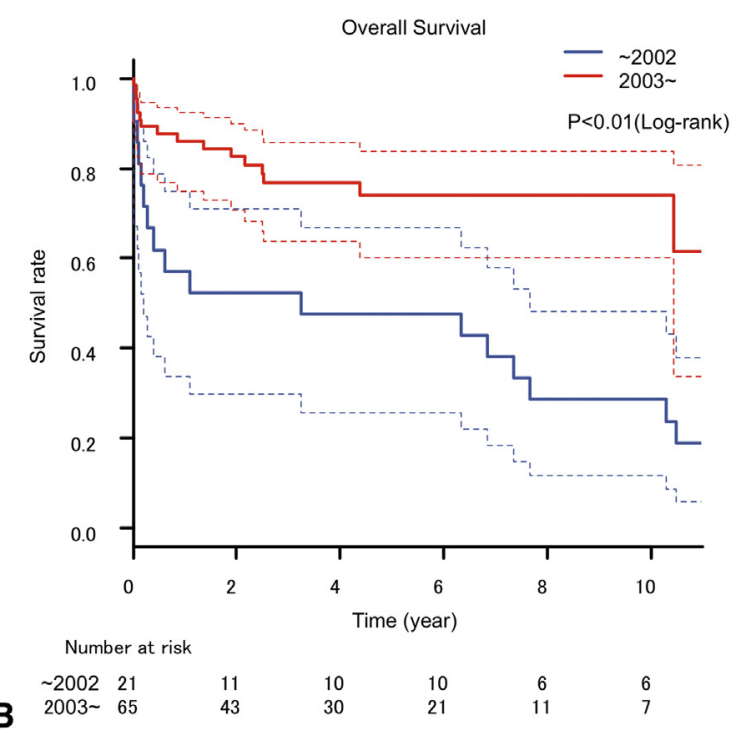

FIGURE 2. A, Kaplan-Meier curves (solid line) with $95 \%$ confidence interval (CI) (dotted line) for the overall and organ survival of all 86 patients. Overall survival at 1 year, 5 years, and 10 years was $79.0 \%$ (95\% CI, 68.7\%-86.2\%; 64 patients at risk), $67.5 \%$ (95\% CI, 55.8\%-76.8\%; 33 patients at risk), and $57.1 \%$ (95\% CI, 43.1\%-68.9\%; 13 patients at risk), respectively. Organ survival at 1 year, 5 years, and 10 years was $79.0 \%(95 \%$ CI, $68.7 \%-86.2 \% ; 64$ patients at risk), $60.3 \%(95 \% \mathrm{CI}, 48.2 \%-70.4 \% ; 30$ patients at risk), and 36.9\% (95\% CI, $22.9 \%-50.9 \% ; 6$ patients at risk), respectively. B, Kaplan-Meier curves (solid line) with $95 \% \mathrm{CI}$ (dotted line) for overall survival according to treatment period. The overall survival during the second period was significantly superior to that during the first period (log-rank $P<.01)$. Overall survival in the second period at 1 year, 5 years, and 10 years was $86.0 \%(95 \% \mathrm{CI}$, $74.9 \%-92.5 \%$; 52 patients at risk), $73.9 \%$ (95\% CI, 60.0\%-83.6\%; 23 patients at risk), and $73.9 \%$ (95\% CI, $60.0 \%-83.6 \% ; 7$ patients at risk), respectively. 
TABLE 2. Univariable risk factor analysis $(n=65)$

\begin{tabular}{|c|c|c|c|c|}
\hline \multirow[b]{2}{*}{ Factor } & \multicolumn{2}{|l|}{ Overall survival } & \multicolumn{2}{|l|}{ Organ survival } \\
\hline & $\begin{array}{c}\text { Hazard ratio } \\
(95 \% \text { Confidence interval })\end{array}$ & $P$ value & $\begin{array}{c}\text { Hazard ratio } \\
(\mathbf{9 5} \% \text { Confidence interval })\end{array}$ & $P$ value \\
\hline \multicolumn{5}{|l|}{ Age (y) } \\
\hline$>11$ & 1 & & 1 & \\
\hline$<11$ & $0.81(0.26-2.5)$ & .71 & $0.69(0.17-2.81)$ & .6 \\
\hline \multicolumn{5}{|l|}{ Gender } \\
\hline Female & 1 & & 1 & \\
\hline Male & $0.7(0.41-1.19)$ & .19 & $0.78(0.22-2.74)$ & .7 \\
\hline \multicolumn{5}{|l|}{ Underlying disease } \\
\hline Cystic fibrosis & 1 & & 1 & \\
\hline No cystic fibrosis & $1.53(0.57-4.11)$ & .4 & $0.45(0.68-3.87)$ & .3 \\
\hline \multicolumn{5}{|l|}{ Preoperative hospitalization } \\
\hline No & 1 & & 1 & \\
\hline Yes & $1.48(0.51-4.33)$ & .48 & $1.91(0.55-6.59)$ & .31 \\
\hline \multicolumn{5}{|l|}{ Preoperative ventilation } \\
\hline No & 1 & & 1 & \\
\hline Yes & $3.85(1.31-11.30)$ & .01 & $3.01(0.70-12.86)$ & .14 \\
\hline \multicolumn{5}{|c|}{ Preoperative extracorporeal membrane oxygenation } \\
\hline No & 1 & & 1 & \\
\hline Yes & $1.88(0.42-8.37)$ & .41 & $1.32(0.15-11.81)$ & .8 \\
\hline \multicolumn{5}{|l|}{ Transplant procedure } \\
\hline Nonlobar & 1 & & 1 & \\
\hline Lobar & $1.07(0.39-2.95)$ & .89 & $1.03(0.28-3.77)$ & .96 \\
\hline \multicolumn{5}{|c|}{ Intraoperative extracorporeal support } \\
\hline No & 1 & & 1 & \\
\hline Yes & $0.74(0.17-3.28)$ & .7 & $1.42(0.21-9.84)$ & .72 \\
\hline \multicolumn{5}{|l|}{ Donor age (y) } \\
\hline$<30$ & 1 & & 1 & \\
\hline$>30$ & $1.58(0.54-4.63)$ & .4 & $0.27(0.03-2.19)$ & .22 \\
\hline \multicolumn{5}{|l|}{ Donor gender } \\
\hline Female & 1 & & 1 & \\
\hline Male & $0.95(0.55-1.62)$ & .84 & $0.95(0.25-3.6)$ & .95 \\
\hline \multicolumn{5}{|l|}{ Ischemia time (h) } \\
\hline$<6$ & 1 & & 1 & \\
\hline$>6$ & $1.02(0.33-3.14)$ & .97 & $2.97(0.69-12.7)$ & .14 \\
\hline \multicolumn{5}{|l|}{ Induction therapy } \\
\hline No & 1 & & 1 & \\
\hline Yes & $0.36(0.14-0.98)$ & .05 & $0.62(0.13-2.91)$ & .55 \\
\hline \multicolumn{5}{|c|}{ Immunosuppression (calcineurin inhibitor) } \\
\hline Tacrolimus & 1 & & 1 & \\
\hline Cyclosporine & $0.04(0-23200.28)$ & .64 & $0.39(0.05-2.97)$ & .36 \\
\hline \multicolumn{5}{|l|}{ Acute rejection } \\
\hline No & 1 & & 1 & \\
\hline Yes & $2.98(1.08-8.2)$ & .03 & $5.42(1.56-18.9)$ & .01 \\
\hline \multicolumn{5}{|l|}{ Postoperative tracheostomy } \\
\hline No & 1 & & 1 & \\
\hline Yes & $2.66(0.98-7.19)$ & .05 & $1.64(0.48-5.61)$ & .43 \\
\hline \multicolumn{5}{|c|}{ Prolonged extracorporeal membrane oxygenation } \\
\hline No & 1 & & 1 & \\
\hline Yes & $1.79(0.68-4.82)$ & .25 & $0.74(0.2-2.82)$ & .66 \\
\hline
\end{tabular}




\begin{tabular}{|c|c|c|c|c|}
\hline \multirow[b]{2}{*}{ Factor } & \multicolumn{2}{|l|}{ Overall survival } & \multicolumn{2}{|l|}{ Organ survival } \\
\hline & $\begin{array}{c}\text { Hazard ratio } \\
(\mathbf{9 5} \% \text { Confidence interval })\end{array}$ & $P$ value & $\begin{array}{c}\text { Hazard ratio } \\
(\mathbf{9 5} \% \text { Confidence interval) }\end{array}$ & $P$ value \\
\hline \multicolumn{5}{|l|}{ Postoperative reoperation } \\
\hline No & 1 & & 1 & \\
\hline Yes & $6.97(2.47-19.68)$ & $<.01$ & $2.56(0.72-9.16)$ & .15 \\
\hline \multicolumn{5}{|c|}{ Postoperative renal replacement therapy } \\
\hline No & 1 & & 1 & \\
\hline Yes & $3.83(0.83-17.71)$ & .09 & $2.34(0.69-11.10)$ & .18 \\
\hline
\end{tabular}

Due to these considerable differences between the 2 time periods as well as the low number of patients in the first era, risk factors for OS and organ survival were only analyzed for patients treated during the second period. In univariable analysis, preoperative mechanical ventilation, induction therapy, acute rejection, postoperative tracheostomy, and postoperative reoperation were significant risk factors for OS $(P<.05)$, whereas for organ survival only acute rejection was identified as a significant risk factor $(P<.05)$ (Table 2). Multivariable analysis revealed preoperative mechanical ventilation was a significant risk factor on both OS and organ survival $(P<.05)$ (Table 3$)$.

In our patient cohort, 17 retransplantations were performed in 14 patients (Table 4). One patient underwent 2 retransplants and another underwent 3 retransplants. The mean time to retransplantation was 1135 days. The indication for retransplantation was CLAD in 12 patients $(85.7 \%)$ and acute rejection or PGD in 2 patients $(14.3 \%)$. Both patients with acute retransplantation died during hospital stay, whereas all patients with elective retransplantation survived. Survival after retransplantation in the CLAD group was $91.7 \%(95 \% \mathrm{CI}, 53.9 \%-98.8 \%)$ at 1 year and $80.2 \%(95 \% \mathrm{CI}, 40.3 \%-87.6 \%)$ at 5 years (Figure 3$)$.

\section{DISCUSSION}

Lung transplantation of pediatric patients differs in many aspects from adult lung transplantation and represents an especially challenging procedure for many reasons. Pediatric patients not only own a different compliance profile and a special lifestyle, but also the low frequency of transplantations in this young age group as well as other issues such as anatomic aspects, scarcity of donor organs, or monitoring of graft function represent the main obstacles to its more frequent use. ${ }^{3,4}$ Because the annual number of pediatric lung transplantations is low-only around 100 worldwide reported cases per year-experiences of individual institutions are rather small. ${ }^{2}$

The Medical University of Vienna has been a supranational referral center for pediatric lung transplant candidates for many years. Therefore, we were able to accumulate a reasonably large experience over a 25 -year time period, which we aimed to summarize in this article. Similar to the international experience, we were able to observe a significant improvement in results over time. Whereas the outcome was $57.1 \%, 47.6 \%$, and $28.6 \%$ at 1,5 , and 10 years during the first period of time, it improved to $86.0 \%$ at 1 year and $73.9 \%$ at 5 and 10 years during the second period. One main reason for this improvement can be seen in the growing experience resulting from a much higher caseload during the second period of time, which actually was almost 3 times as high as during the first period.

The further discussion and analysis will therefore mainly focus on this second period. It reflects the standard of treatment during the most recent 13 years, whereas the early period owns more historic aspects. Especially the observed 5-year survival rate of $73.9 \%$ during the second period compares favorably to data from the registry $(56.4 \%$ for the period $2008-2013)$, but also to results from other single centers $(44 \%$ for 1987-2007 from Hannover, 61\% for 1991-2009 from St Louis-only patients with idiopathic pulmonary artery hypertension included). ${ }^{5,6}$ This outcome was found to be even better than the outcome described for the adult population in the registry for a similar period of time (1 year, $82.7 \%$ and 5 years, $55.4 \%$ for the period 2005-2012). ${ }^{2}$ Compared with the outcome of our own adult patient population transplanted within the same time period (1-year OS, $83.1 \% \quad[95 \% \quad \mathrm{CI}$, $80.4 \%-85.5 \%]$ and 5-year OS, $71.2 \% \quad[95 \%$ CI, 68.3\%-75.3\%]) (Figure E3) similar results were observed. Additionally, our OS on conditional 1-year survival in the late period was superior to that in the early period (Figure E4) $(P=.04)$, which is in contrast to published results from the United Network for Organ Sharing database. $^{7}$ These findings suggest that meanwhile the difference in results between adult and pediatric populations have leveled out, not only due to improvements in perioperative, but also in long-term management.

However, analysis of organ survival rates gives a somewhat different picture, because the 10-year organ survival rate of $52.1 \%$ during the second period was clearly lower than the 10 -year OS of $73.9 \%$. This difference was mainly caused by a very successful retransplantation strategy. Twelve patients received a total of 15 elective retransplantations for CLAD with a 1-year survival rate of $91.7 \%$ and a 5-year survival rate of $80.2 \%$. Chronic rejection 
TABLE 3. Multivariable risk factor analysis $(n=65)$

\begin{tabular}{|c|c|c|c|c|c|}
\hline \multirow[b]{2}{*}{ Factor } & \multirow[b]{2}{*}{ Present } & \multicolumn{2}{|c|}{ Overall survival } & \multicolumn{2}{|c|}{ Organ survival } \\
\hline & & $\begin{array}{l}\text { Hazard ratio (95\% } \\
\text { Confidence interval) }\end{array}$ & $P$ value & $\begin{array}{l}\text { Hazard ratio (95\% } \\
\text { Confidence interval) }\end{array}$ & $P$ value \\
\hline \multirow[t]{2}{*}{ Preoperative ventilation } & No & 1 & & 1 & \\
\hline & Yes & $4.15(1.08-15.87)$ & .04 & $12.1(1.71-85)$ & .01 \\
\hline \multirow{2}{*}{$\begin{array}{l}\text { Preoperative extracorporeal } \\
\text { membrane oxygenation }\end{array}$} & No & 1 & & 1 & \\
\hline & Yes & $0.5(0.09-2.93)$ & .44 & $0.27(0.02-3.92)$ & .33 \\
\hline \multirow[t]{2}{*}{ Induction therapy } & No & 1 & & 1 & \\
\hline & Yes & $0.48(0.17-1.39)$ & .12 & $4.24(0.43-41.73)$ & .21 \\
\hline
\end{tabular}

and the occurrence of CLAD remains a significant problem late after lung transplantation. Reduction of cumulative incidence of CLAD was not significant during the second period (Figure E5) $(P=.21)$.

The results after elective retransplantation were remarkably good in this series, which is in contrast to the published experience. Pediatric retransplantation is very rare, with only 5 to 8 procedures being reported annually to the ISHLT registry and outcomes are worse than those after primary transplantation, with a 1 -year survival of $56.9 \%$ and a 5year survival of $33.1 \% .^{2}$ Only recently have better results been reported by a single center with a 5-year survival of more than $40 \%{ }^{8}$ In sharp contrast to these findings but in parallel to the experience in adult populations, ${ }^{9}$ early acute retransplantation within 12 months after primary lung transplantation had very poor outcomes in our center, with both patients (from the early cohort) dying within 30 days. As a consequence of this, we abandoned early acute retransplantation, although we have not seen any need for it in recent years.

When comparing our results to registry data, the donor and recipient demographic characteristics, such as age distribution and underlying disease, were very similar to those

TABLE 4. Retransplantation data $(n=14)$

\begin{tabular}{lc}
\hline \multicolumn{1}{c}{ Variable } & Result \\
\hline No. of retransplantations & \\
1 & 12 \\
2 & 1 \\
3 & 1 \\
Indication for first retransplantation & \\
$\quad$ Chronic lung allograft dysfunction & $12(85.7)$ \\
$\quad$ Acute rejection or primary graft dysfunction & $2(14.3)$ \\
Time to first retransplantation (d) & $1638.7(382-2770)$ \\
Retransplantation for acute rejection or primary & $49.5(39-60)$ \\
$\quad$ graft dysfunction & \\
30-d mortality & $2(100)$ \\
Retransplantation for acute rejection or primary & \\
$\quad$ graft dysfunction & \\
\hline Values are presented as $n, n(\%)$, or median (range).
\end{tabular}

in the ISHLT registry. ${ }^{2}$ However, there were a number of other factors that might have contributed to the improvement of results and that need to be addressed. A very special feature of our pediatric lung transplantations was the use of ECMO for intraoperative cardiorespiratory support. The majority of patients $(90.8 \%)$ from the second period were transplanted while on cardiorespiratory support, which was ECMO in 58 out of 59 patients. ECMO has replaced $\mathrm{CPB}$ as the routine intraoperative support completely, due to its many advantages such as a decreased systemic inflammatory response, the possibility to avoid full heparinization while at the same time offering completely s intraoperative conditions, and especially the protection of the first transplanted lung from overflow. ${ }^{10-16}$

As a special treatment strategy, we have prolonged intraoperative ECMO into the postoperative period in about $33 \%$ of patients. Criteria for prolongation were marginal quality of the donor organ, increasing need for more aggressive ventilation at the end of the intraoperative ECMO support, or a high-risk recipient. In these situations, the central ECMO was transferred into the groin and continued for another 24 to 48 hours to provide prolonged controlled reperfusion. Most likely, this is among the reasons why we have not seen acute graft failure during the past years. This concept also allowed us to handle a quite sick patient population, which is demonstrated by the fact that $9.2 \%$ of patients were already receiving preoperative ECMO bridging and $13.8 \%$ were receiving mechanical ventilation at the time of transplantation. ECMO support as a bridge to transplantation is being increasingly used in selected patients, and satisfying outcomes have been documented in several single-center reports. ${ }^{17-19}$ Also in this cohort of pediatric patients, neither preoperative ECMO bridging nor postoperative ECMO prolongation had a negative influence on both OS and organ survival, as calculated by uni- and multivariable analysis.

The high percentage of advanced and urgent patients also resulted in the need to apply different forms of size reduction procedures. This increased the pool of available donor organs by allowing us to use larger and oversized lungs for transplantation. ${ }^{20}$ This strategy resulted in the use of lobar 


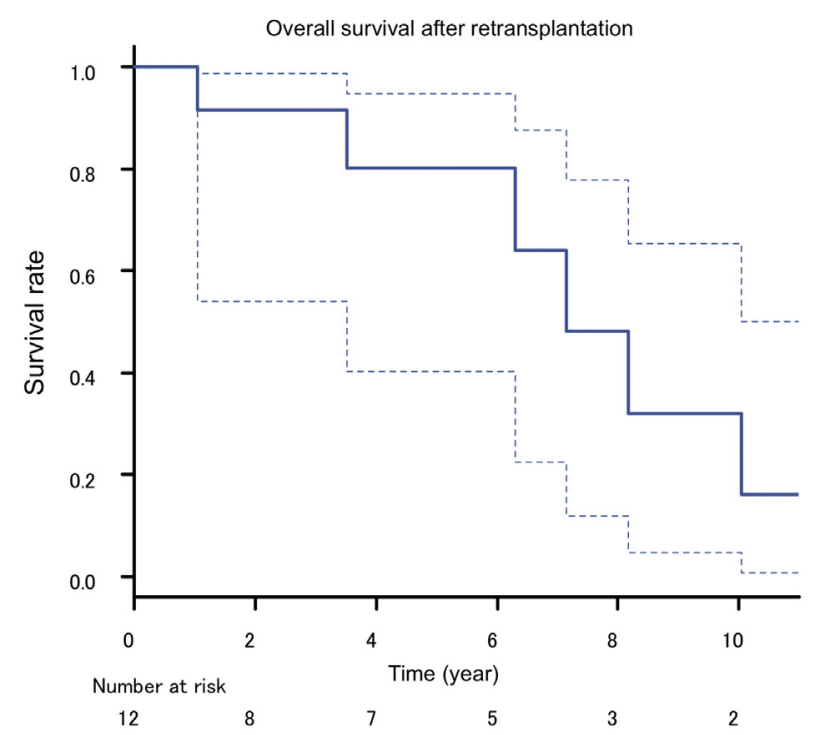

FIGURE 3. Overall survival after retransplantation in patients with chronic lung allograft dysfunction $(\mathrm{n}=12)$. The overall survival at 1 year was $91.7 \%$ (95\% confidence interval, 53.9\%-98.8\%; 11 patients at risk) and at 5 years was $80.2 \%$ (95\% confidence interval, $40.3 \%$ $87.6 \% ; 6$ patients at risk).

transplantation in more then one-third of patients during the second period of time. Similar to use of prolonged ECMO, lobar transplantation had no negative influence on survival as calculated by uni- and multivariable analysis.

With regard to immunosuppression, 2 important factors have to be pointed out. Induction therapy mainly with alemtuzimab was administered in $76 \%$ of patients during the second period and tacrolimus-based maintenance immunosuppression was used us in all patients but 1 . Both might have contributed to the reduction in CLAD in the population of the second period, ${ }^{21}$ although there are certainly other factors of influence for this as well.

When trying to identify risk factors for OS, univariable analysis revealed that mechanical ventilation before transplantation, lack of induction therapy, episode of acute rejection, postoperative tracheostomy, and postoperative reoperation had significant negative influence, whereas multivariable analysis identified only preoperative mechanical ventilation. With regard to organ survival, preoperative mechanical ventilation was also a significant risk factor in both uni- and multivariable analysis. However, interpretation of these results must be performed very cautiously, because postoperative factors have to be seen as the consequence of a difficult operative course. For this reason, preoperative mechanical ventilation has to be considered as the only relevant predictive risk factor identified in this analysis.

The main limitation of this study is its singleinstitutional nature. Treatment plans, including surgical techniques and perioperative management, changed over time. Also, the type of perfusion solution changed from Euro-Collins to Perfadex within the study period. This could have added to the improved outcome of patients transplanted in the later time period. Another limitation is the relatively small sample size, which decreases the power of any statistical analysis. However, given the worldwide low number of pediatric lung transplantations, we believe that the data given here are of importance for a better understanding of the current position of pediatric lung transplantation.

\section{CONCLUSIONS}

Outcome of pediatric lung transplantation has significantly improved over the past 25 years and has become comparable to that of adult transplantation. Elective retransplantations for pediatric patients were performed successfully, and influenced strongly to improve long-term OS.

\section{Conflicts of Interest Statement}

Authors have nothing to disclose with regard to commercial support.

The authors thank Dr Arima, Department of Preventive Medicine and Public Health, Fukuoka University, for his support in statistical analysis in this study.

\section{References}

1. Mendeloff EN. The history of pediatric heart and lung transplantation. Pediatr Transplant. 2002;6:270-9.

2. Goldfarb SB, Benden C, Edwards LB, Kucheryavaya AY, Dipchand AI, Levvey BJ, et al. The Registry of the International Society for Heart and Lung Transplantation: eighteenth official pediatric lung and heart-lung transplantation report-2015; focus theme: early graft failure. J Heart Lung Transplant. 2015;34: 1255-63.

3. Kirkby S, Hayes D Jr. Pediatric lung transplantation: indications and outcomes. J Thorac Dis. 2014;6:1024-31.

4. Hayes D Jr, Benden C, Sweet SC, Conrad CK. Current state of pediatric lung transplantation. Lung. 2015;193:629-37.

5. Gorler H, Struber M, Ballmann M, Müller C, Gottlieb J, Warnecke G, et al. Lung and heart-lung transplantation in children and adolescents: a long-term singlecenter experience. J Heart Lung Transplant. 2009;28:243-8.

6. Goldstein BS, Sweet SC, Mao J, Huddleston CB, Grady RM. Lung transplantation in children with idiopathic pulmonary arterial hypertension: an 18-year experience. J Heart Lung Transplant. 2011;30:1148-52.

7. Zafar F, Heinle JS, Schecter MG, Rossano JW, Mallory GB Jr, Elidemir O, et al. Two decades of pediatric lung transplant in the United States: have we improved? J Thorac Cardiovasc Surg. 2011;141:828-32.

8. Müller C, Görler H, Ballmann M, Gottlieb J, Simon AR, Strüber M, et al. Pulmonary retransplantation in paediatric patients: a justified therapeutic option? A single-centre experience. Eur J Cardiothorac Surg. 2011;39:201-5.

9. Scully BB, Zafar F, Schecter MG, Rossano JW, Mallory GB Jr, Heinle JS, et al. Lung retransplantation in children: appropriate when selectively applied. Ann Thorac Surg. 2011;91:574-9.

10. Aigner C, Wisser W, Taghavi S, Lang G, Jaksch P, Czyzewski D, et al. Institutional experience with extracorporeal membrane oxygenation in lung transplantation. Eur J Cardiothorac Surg. 2007;31:468-73.

11. Machuca TN, Collaud S, Mercier O, Cheung M, Cunningham V, Kim SJ, et al Outcomes of intraoperative extracorporeal membrane oxygenation versus cardiopulmonary bypass for lung transplantation. J Thorac Cardiovasc Surg. 2015;149: 1152-7.

12. Ius F, Kuehn C, Tudorache I, Sommer W, Avsar M, Boethig D, et al. Lung transplantation on cardiopulmonary support: venoarterial extracorporeal membrane 
oxygenation outperformed cardiopulmonary bypass. J Thorac Cardiovasc Surg. 2012;144:1510-6.

13. Ius F, Sommer W, Tudorache I, Avsar M, Siemeni T, Salman J, et al. Five-year experience with intraoperative extracorporeal membrane oxygenation in lung transplantation: indications and midterm results. J Heart Lung Transplant. 2016;35:49-58.

14. Bermudez CA, Shiose A, Esper SA, Shigemura N, D'Cunha J, Bhama JK, et al. Outcomes of intraoperative venoarterial extracorporeal membrane oxygenation versus cardiopulmonary bypass during lung transplantation. Ann Thorac Surg. 2014:98:1936-42.

15. Biscotti M, Yang J, Sonett J, Bacchetta M. Comparison of extracorporeal membrane oxygenation versus cardiopulmonary bypass for lung transplantation. J Thorac Cardiovasc Surg. 2014;148:2410-5.

16. Hoechter DJ, von Dossow V, Winter H, Müller HH, Meiser B, Neurohr C, et al. The Munich Lung Transplant Group: intraoperative extracorporeal circulation in lung transplantation. Thorac Cardiovasc Surg. 2015;63: 706-14.
17. Hayes D Jr, McConnell PI, Tobias JD, Whitson BA, Preston TJ, Yates AR, et al. Survival in children on extracorporeal membrane oxygenation at the time of lung transplantation. Pediatr Transplant. 2015;19:87-93.

18. Lang G, Taghavi S, Aigner C, Rényi-Vámos F, Jaksch P, Augustin V, et al. Primary lung transplantation after bridge with extracorporeal membrane oxygenation: a plea for a shift in our paradigms for indications. Transplantation. 2012;9:729-36.

19. Schmidt F, Sasse M, Boehne M, Mueller C, Bertram H, Kuehn C, et al. Concept of "awake venovenous extracorporeal membrane oxygenation" in pediatric patients awaiting lung transplantation. Pediatr Transplant. 2013;17:224-30.

20. Aigner C, Winkler G, Jaksch P, Ankersmit J, Marta G, Taghavi S, et al. Sizereduced lung transplantation: an advanced operative strategy to alleviate donor organ shortage. Transplant Proc. 2004;36:2801-5.

21. Gruber S, Eiwegger T, Nachbaur E, Tiringer K, Aigner C, Jaksch P, et al. Lung transplantation in children and young adults: a 20-year single-centre experience. Eur Respir J. 2012;40:462-9.

Key Words: lung transplantation, pediatric, retransplantation 


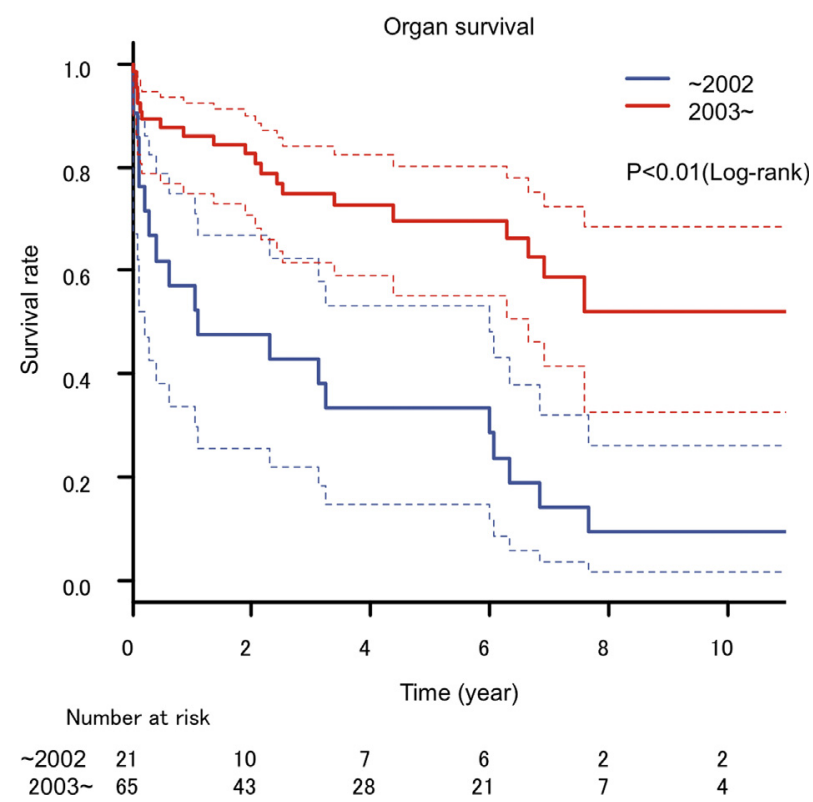

FIGURE E1. Kaplan-Meier curves (solid line) with $95 \%$ confidence interval (CI) (dotted line) for organ survival according to treatment period. The organ survival during the second period was significantly superior to that during the first period ( $\log$-rank $P<.01)$. Organ survival during the second period at 1 year, 5 years, and 10 years was $86.0 \%$ (95\% CI, $74.9 \%$ $92.5 \% ; 52$ patients at risk), $69.7 \%(95 \%$ CI, $55.2 \%-80.3 \% ; 23$ patients at risk), and $52.1 \%(95 \% \mathrm{CI}, 32.6 \%-68.4 \%$; 4 patients at risk), respectively.

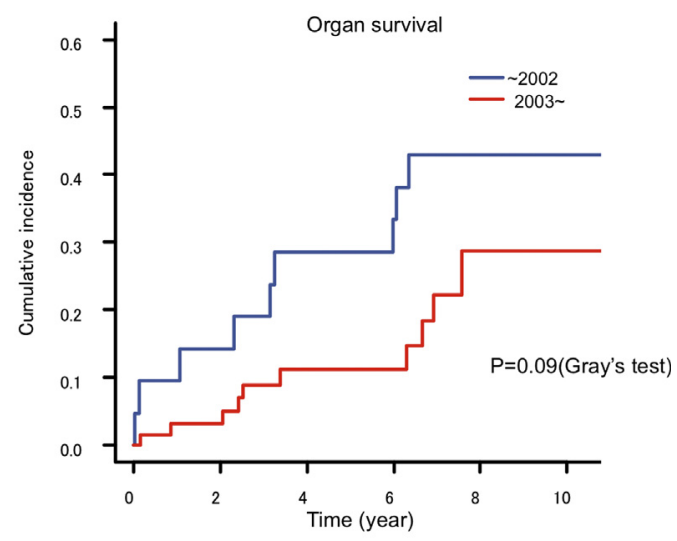

$\sim 2002$\begin{tabular}{|c|c|c|c|c|c|c|}
\hline Graft death (\%) & 0 & 14.3 & 28.6 & 33.3 & 42.9 & 42.9 \\
\hline $95 \% \mathrm{Cl}$ & & $3.4-32.8$ & $11-49.1$ & $14.1-54$ & $20.7-63.4$ & $20.7-63.4$ \\
\hline $\mathrm{N}$ at risk & 21 & 10 & 7 & 6 & 2 & 2 \\
\hline
\end{tabular}
\begin{tabular}{|c|c|c|c|c|c|c|}
\hline Graft death $(\%)$ & 0 & 3.2 & 11.2 & 11.2 & 28.8 & 28.8 \\
\hline $95 \% \mathrm{Cl}$ & & $0.1-9.8$ & $4.4-21.4$ & $4.4-21.4$ & $12.7-47.2$ & $12.7-47.2$ \\
\hline $\mathrm{N}$ at risk & 65 & 43 & 28 & 21 & 7 & 4 \\
\hline
\end{tabular}

FIGURE E2. Cumulative incidence of graft death according to treatment period. The cumulative incidence during the first period was $9.5 \%$ at 1 year (95\% confidence interval [CI], 1.5\%-26.7\%; 13 patients at risk), $28.6 \%$ at 5 years ( $95 \%$ CI, $11.0 \%-49.1 \% ; 7$ patients at risk), and $42.9 \%$ at 10 years (95\% CI, 20.7\%-63.4\%; 2 patients at risk), respectively. The cumulative incidence during the second period was $3.2 \%$ at 1 year $(95 \% \mathrm{CI}, 0.6 \%$ $9.8 \% ; 54$ patients at risk), $11.2 \%$ at 5 years $(95 \% \mathrm{CI}, 4.4 \%-21.4 \% ; 25$ patients at risk), and $28.8 \%$ at 10 years $(95 \% \mathrm{CI}, 12.7 \%-47.2 \% ; 4$ patients at risk), respectively. The cumulative incidence of graft death during the second period was superior with marginal significance to that during the first period (Gray's test $P=.09$ ).

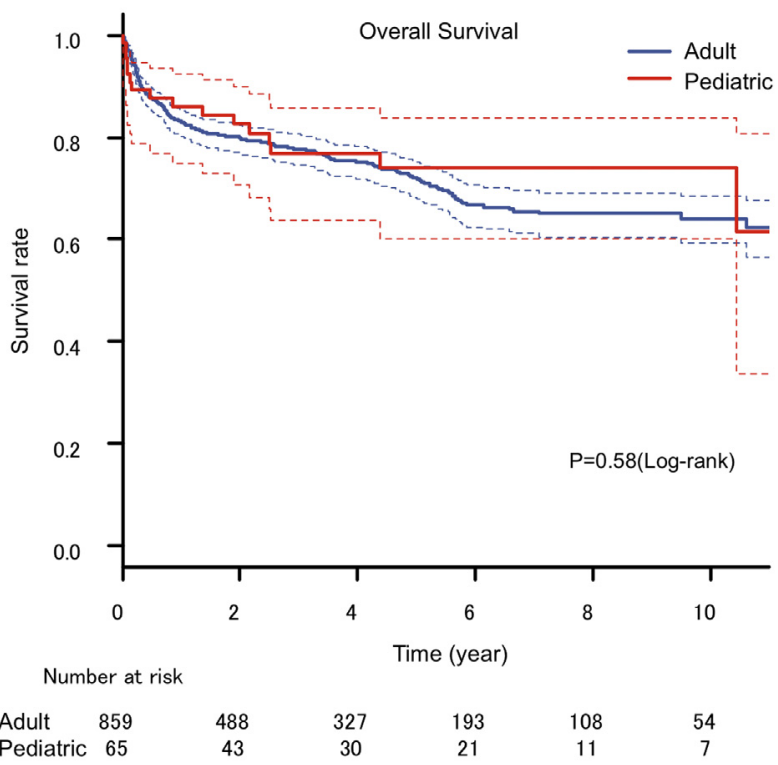

FIGURE E3. Kaplan-Meier curves (solid line) with $95 \%$ confidence interval (CI) (dotted line) for overall survival in comparison between adults and pediatric patients during 2003 to 2015 . The overall survival in pediatric cohort was equal to that in adults ( $\log$-rank $P=.58)$. 


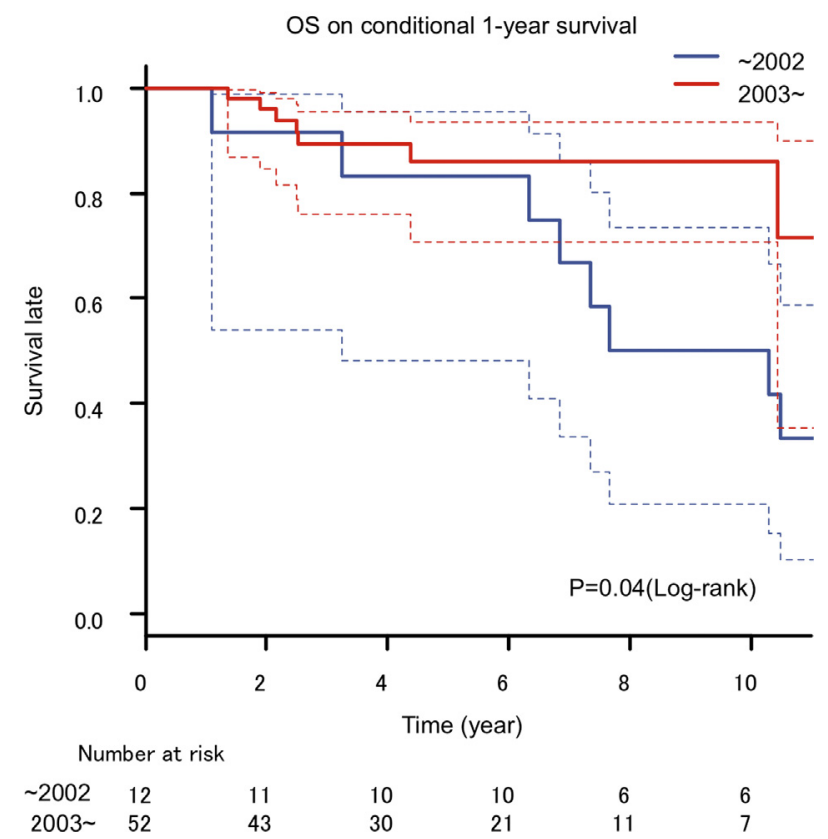

FIGURE E4. Kaplan-Meier curves (solid line) with $95 \%$ confidence interval (CI) (dotted line) for overall survival (OS) on conditional 1-year survival according to treatment period. OS during the first period was $83.3 \%$ $(95 \% \mathrm{CI}, 48.2 \%-95.6 \% ; 10$ patients at risk) at 5 years, and $50 \%(95 \% \mathrm{CI}$, $20.9 \%-73.6 \% ; 6$ patients at risk) at 10 years, respectively. OS during the second period was $85.9 \%$ (95\% CI, 70.8\%-93.5\%; 24 patients at risk) at 5 years, and $85.9 \%(95 \% \mathrm{CI}, 70.8 \%-93.5 \% ; 7$ patients at risk) at 10 years, respectively. OS during the second period remained superior compared with the first period $(P=.04)$.

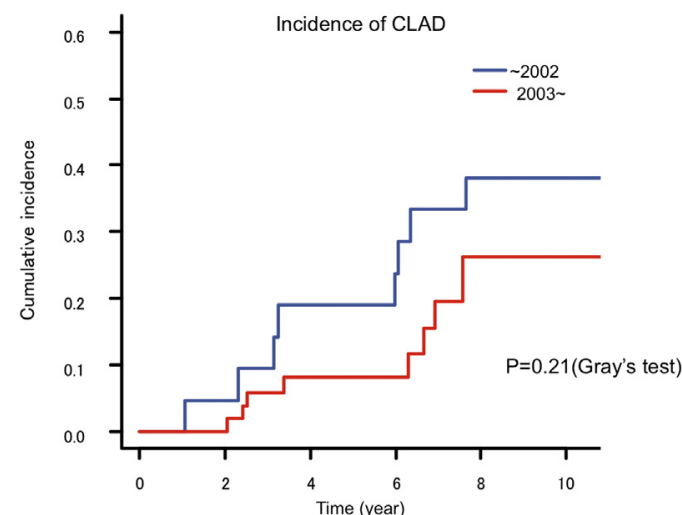

\begin{tabular}{|c|c|c|c|c|c|c|c|}
\hline \multirow{3}{*}{$\sim 2002$} & CLAD (\%) & 0 & 4.8 & 19 & 23.8 & 38.1 & 38.1 \\
\hline & $95 \% \mathrm{Cl}$ & & $0-20.6$ & $5.5-38.8$ & $8-44.2$ & $16.9-59.2$ & $16.9-59.2$ \\
\hline & $\mathrm{N}$ at risk & 21 & 10 & 7 & 6 & 2 & 2 \\
\hline \multirow{3}{*}{ 2003 } & CLAD (\%) & 0 & 0 & 8.2 & 8.2 & 26.2 & 26.2 \\
\hline & $95 \% \mathrm{Cl}$ & & & 2.6-18.1 & 2.6-18.1 & $10.5-45.1$ & $10.5-45.1$ \\
\hline & $\mathrm{N}$ at risk & 65 & 43 & 28 & 21 & 7 & 4 \\
\hline
\end{tabular}

FIGURE E5. Cumulative incidence of chronic lung allograft dysfunction $(C L A D)$ according to treatment period. No significant difference in incidence of CLAD was observed between time periods (Gray's test $P=.21)$. CI, Confidence interval. 